\title{
Prof. Dr. habil. Norbert Honsza zum Gedenken
}

Am 16. Juli 2020 verschied Prof. Dr. habil. Norbert Honsza, einer der angesehensten europäischen Literaturwissenschaftler, ein Germanist von Weltrang und ein unermüdlicher Verfechter der polnisch-deutschen Annäherung, die er - ein stolzer Oberschlesier - lebenslang als wichtigste Aufgabe erachtete. Geboren am 23. Juni 1933 in Wodzisław Śląski wuchs er in einer multikulturellen Umgebung auf; dies ließ ihn dann die Geschichte seiner Heimat als die einer Konfliktregion interpretieren, was wiederum seinen Werdegang als Mensch und Gelehrter mitgeprägt haben musste.

Mit der Promotion, die er 1963 an seiner Heimatuniversität in Wrocław/Breslau erlangte, begann seine internationale Karriere, die ihm rasch einen Ehrenplatz in der gelehrten Welt sicherte. Bereits 1970 konnte er seine Habilitationsschrift einreichen, die ihm den Ruf eines versierten Thomas Mann-Kenners brachte. Seine organisatorische Höchstleitung in der ersten Periode seines akademischen Werdegangs war die im gleichen Jahr gegründete Abteilung für Zeitgenössische Deutschsprachige Literatur und Kultur, deren wissenschaftliche Arbeit nun von seinen Studierenden erfolgreich weitergeführt wird und die auch heute das wichtigste Element in der Struktur des Instituts für Germanistik der Universität Wrocław darstellt.

Prof. Dr. habil. Norbert Honsza war nicht nur ein Gelehrter, der jahrzehntelang zu den führenden Persönlichkeiten der Geisteswissenschaften gezählt wurde, sondern auch Dreh- und Angelpunkt des wissenschaftlichen Lebens - mit zahlreichen Tagungen, Autorenlesungen, Texteditionen, öffentlichen Vorträgen und anderen Aktivitäten trug er erheblich zur Popularisierung deutschsprachiger Literatur in Polen bei. Selbst in der schlimmsten Zeit nach der Verhängung des Kriegsrechts in Polen gelang es ihm immer wieder Wissenschaftler aus Berlin, München, Hamburg, Wien, Salzburg und Graz nach Wrocław einzuladen und dadurch einer der polnischen Germanistik drohenden Abgeschnittenheit entgegenzuwirken. Norbert Honsza war es aber auch, der schon seit den frühen siebziger Jahren eine durchaus effiziente „lebendige“ Literaturgeschichte pflegte: jedes Jahr kamen namhafte Schriftsteller aus Deutschland und Österreich, die vor Breslauer Studierenden aus ihren Texten lasen; auch diese Tradition wird jetzt von seinen ehemaligen Studierenden dankend fortgesetzt. Die von ihm geleiteten germanistischen Konferenzen galten jeweils gleichermaßen als Manifeste der Wissenschaftsfreiheit und 
als Stätten des Dialogs; auch dies war ein Ergebnis seiner raren Kunst, Menschen für seine hehren Ideen zu gewinnen: Fast immer kamen da nämlich die beiden Parteien des literaturwissenschaftlichen Streites zu Wort - Autoren und die Interpreten ihrer Werke. Beinahe zu einem Generationserlebnis wurde für Hunderte junger polnischer Germanisten die Begegnung mit Günter Grass, der - wie viele andere vor und nach ihm - der Einladung seines Freundes und Biographen Norbert Honsza folgte und eine ihm gewidmete Tagung in Karpacz mit seiner Anwesenheit beehrte, um anschließend eine Lesung an der Universität Wrocław zu halten. Auch ein anderer deutscher Nobelpreisträger gehörte zum Freundeskreis des Breslauer Germanisten und zwar Heinrich Böll, dessen Werk Professor Honsza in einigen Büchern und mehreren Aufsätzen sowohl dem deutschen als auch dem polnischen Leser auslegte.

Als Interpret bevorzugte Norbert Honsza die Literatur aus der Bundesrepublik, der er die meisten seiner vielen Monographien und Sammelwerke widmete. Ihm waren aber auch die neuesten Tendenzen der österreichischen und der Schweizer Literatur wohlbekannt. Er war einer der ersten europäischen Literaturwissenschaftler, die die Größe des Österreichers Peter Handke zu erkennen vermochten, obwohl er den umstrittenen Nobelpreisträger - selbst nachdem dieser durch den Beschluss der Schwedischen Akademie es auf den Dichterparnass geschafft hatte - mit gewisser Distanz betrachtete. Mit großer Sympathie betrachtete er aber das Herkunftsland des kontroversen Autors: 1982 gründete er nämlich die Breslauer Filiale der Gesellschaft Polen - Österreich und wurde ihr langjähriger Vorsitzender. Auch diese Gründung erwies sich als ein organisatorischer Erfolg - es entstand ein willkommenes Diskussionsforum, eine Begegnungsstätte für alle, die an den kulturellen Errungenschaften der Donaurepublik interessiert waren. Auch hier, ähnlich wie im akademischen Bereich, fand er willige Studierende, die heutzutage auf seine klugen Ideen zurückgreifen und durch zahlreiche Aktivitäten die führende Position der Breslauer Abteilung in Polen gewährleisten.

Als Universitätslehrer erwarb sich Norbert Honsza Ansehen im In- und Ausland. Außer an seiner Heimatuniversität lehrte er an einigen polnischen und als Gastprofessor an mehreren ausländischen Hochschulen. Er hielt viele Gastvorträge und absolvierte mehrere Auslandsaufenthalte als Stipendiat wissenschaftlicher Institutionen, u.a. der Humboldt-Stiftung. Unter seiner Leitung entstanden über 50 Doktorarbeiten; seine geistigen Nachfolger, viele von ihnen bereits im Professorenstand beheimatet, sind jetzt an fast jeder Universität in Polen wie auch an etlichen ausländischen Hochschulen tätig.

Unter seinen unzähligen Publikationen, darunter etwa 50 Büchern und vielen Hunderten von Aufsätzen und Besprechungen, gibt es viele, die große Beachtung fanden: zum Kanon der germanistischen Literaturwissenschaft gehören seine Monographien über Grass, Böll, Heine, Karl May und über literarische Gruppen in deutschsprachigen Ländern ebenso wie seine Sammelbände über Handke und andere österreichische Autoren; bleibenden Wert behalten auch seine Darstellungen 
zur Geschichte der deutschen Literatur. Von großem Belang ist seine publizistische Tätigkeit, die u.a. in der von ihm gegründeten Zeitschrift „Annäherungen Polen Deutschland“ / „Zbliżenia Polska - Niemcy“ zutage trat.

Prof. Dr. habil. Norbert Honsza wurde mit zahlreichen Preisen und Auszeichnungen bedacht. 2003 wurde ihm der Kulturpreis Schlesien des Landes Niedersachsen und 2012 der Preis der Gesellschaft der Freunde Schlesiens verliehen. Die allerhöchste Würdigung ist aber die Achtung, die er sein Leben lang als Lehrer und Gelehrter unter seinen Studierenden und Mitarbeitern genoss. Er bleibt in unserer Erinnerung als derjenige erhalten, der uns den Weg zur Erkenntnis wies, keinen leichten übrigens, denn es war einer, der über die Literatur führt. Als einer seiner dankbaren Schüler versprach ich ihm an seiner Bahre, dass wir sein großes Lebenswerk fortführen werden. Und dieses Versprechen will ich hier noch einmal bekräftigen.

Edward Białek 